\title{
FATORES RELACIONADOS À AUTOPERCEPÇÃO DE SAÚDE ORAL EM NONAGENÁRIOS E CENTENÁRIOS NA COVID-19: ESTUDO AMPAL
}

Camila Dalbosco Gadenz; Escola de Medicina da PUCRS, Porto Alegre, Brasil; camiladgadenz@gmail.com Josemara de Paula Rocha*; Escola de Medicina da PUCRS, Porto Alegre, Brasil; josemara.rocha@hotmail.com Renata Breda Martins*; Escola de Medicina da PUCRS, Porto Alegre, Brasil; nutrirenatamartins@gmail.com Álvaro Luiz Fortes*; Escola de Medicina da PUCRS, Porto Alegre, Brasil; alvarolforte@gmail.com Marlon Cássio Pereira Grigol*; Escola de Medicina da PUCRS, Porto Alegre, Brasil; marlonfisio@gmail.com Ângelo José Gonçalves Bós*; Escola de Medicina da PUCRS, Porto Alegre, Brasil; angelo.bos@pucrs.br

*Projeto de extensão Atenção Multiprofissional ao Longevo (AMPAL) da PUCRS, Porto Alegre, Brasil

\section{RESUMO}

Introdução: A saúde bucal pode influenciar a saúde geral. Nonagenários e centenários frequentemente apresentam alterações bucais que necessitam acompanhamento odontológico. A quarentena pode restringir o acesso a esse acompanhamento e favorecer problemas locais e sistêmicos. Objetivo: Caracterizar autopercepção de saúde oral de nonagenários e centenários durante o isolamento social para a COVID-19. Métodos: Estudo observacional e transversal envolvendo nonagenários e centenários do Projeto Atenção Multiprofissional ao Longevo, avaliados por smartphone entre abril e agosto de 2020, usando como critérios de inclusão idade acima ou igual a 90 anos e residir em Porto Alegre. As variáveis investigadas foram autopercepção de saúde oral (APSO, variável dependente), geral (APSG) e da mastigação (APSM), gênero, faixa etária, estado conjugal, presença de lesões orais e atendimento odontológico nas duas últimas semanas. Foram realizadas frequências absolutas e relativas (proporção). Resultados: Quarenta e oito participantes conseguiram responder a APSO. A maior parte (33; 69\%) considerou a APSO boa, essa proporção foi maior entre os homens $(11 ; 85 \%)$, centenários $(5 ; 83 \%)$, casados $(22 ; 75 \%)$, com APSG boa $(21 ; 85 \%)$, APSM boa (29; 93\%) e com menor frequência de lesões na cavidade oral $(2 ; 4 \%)$. A frequência de atendimento odontológico foi baixa, apenas um participante, que considerava sua APSO boa. Conclusão: A APS oral boa foi mais frequente nos homens, centenários, casados com APSG e APSM boas. Apesar de 15\% dos longevos apresentarem autopercepção de saúde oral ruim somente um recebeu atendimento odontológico. Concluímos que nonagenários e centenários estão negligenciando os cuidados de saúde oral.

Palavras-chaves: Idoso de 80 Anos ou mais; Saúde Bucal; COVID-19. 